\title{
Ferrites for Global Environmental Protection Technology
}

\author{
Y. TAMAURA
}

Tokyo Institute of Technology, Research Center for Carbon Recycling and Utilization,

Ookayama, Meguro-ku, Tokyo 152, Japan

\begin{abstract}
Topics on utilization of the ferrite for the global environmental protection technology were reviewed; 1) waste water treatment process (ferrite process), 2) $\mathrm{CO}_{2}$ decomposition with an excess ferrite for utilization of carbon as solar $\mathrm{H}_{2}$ carrier, 3) solar energy conversion into $\mathrm{H}_{2}$ energy, and 4) hybridization process for mixing solar and fossil energies. Recent studies on the ferrite for the global environmental protection are opening a new application of the ferrites.
\end{abstract}

\section{INTRODUCTION}

Global environmental problem has various aspects of global warming, ozone depletion, contamination with hazardous chemicals, fossil energy shortage, nuclear energy problem, deforestation, rapid growth of the world's population, etc. Recently, ferrites have been studied from the viewpoint of global environmental protection, and some technology is practically applied. These studies are categorized into the following 4 subjects; 1) waste water treatment process (ferrite process), 2) $\mathrm{CO}_{2}$ decomposition with an excess ferrite for utilization of carbon as solar $\mathrm{H}_{2}$ carrier, 3) solar energy conversion into $\mathrm{H}_{2}$ energy, and 4) hybridization process for mixing solar and fossil energies.

The ferrite formation reaction by the wet process has been applied to the treatment of the waste water containing heavy metal ions.

The reactivity of the cation excess ferrite has been studied for the $\mathrm{CO}_{2}$ recovery and concentration from the exhaust gas. This technology is applicable for the solar $\mathrm{H}_{2}$ conversion into $\mathrm{CH}_{4}$ at the combined plant of the hybridized solar thermal plant (HST-plant) and the solar thermochemical plant where the concentrated solar energy will be converted into solar $\mathrm{H}_{2}$ by a solar thermochemical process (STC- $\mathrm{H}_{2}$-plant).

The endothermic reaction, which includes the reduction of the metal oxides or ferrites, can be used for the solar thermochemical process. In this process, the concentrated solar energy is converted into chemical energy of the reduced form of the metal oxides or ferrites. When those reduced forms can decompose water to generate $\mathrm{H}_{2}$, we can produce solar $\mathrm{H}_{2}$ using those oxides and ferrites.

Ferrites are very useful materials which were invented by Dr. Takei at TIT in Japan. In industrial applications, a number of significant new developments have been achieved. Recent studies on the ferrite for the global environmental protection are opening a new application of the ferrites. The present paper briefly reviews the studies on those new technologies.

\section{FERRITE PROCESS FOR WASTE WATER TREATMENT}

In the treatment of the heavy metal waste water, there are two important points; 1) complete removal of the heavy metal ions from the waste water and 2) no redissolution of the heavy metal ions from the sludge.

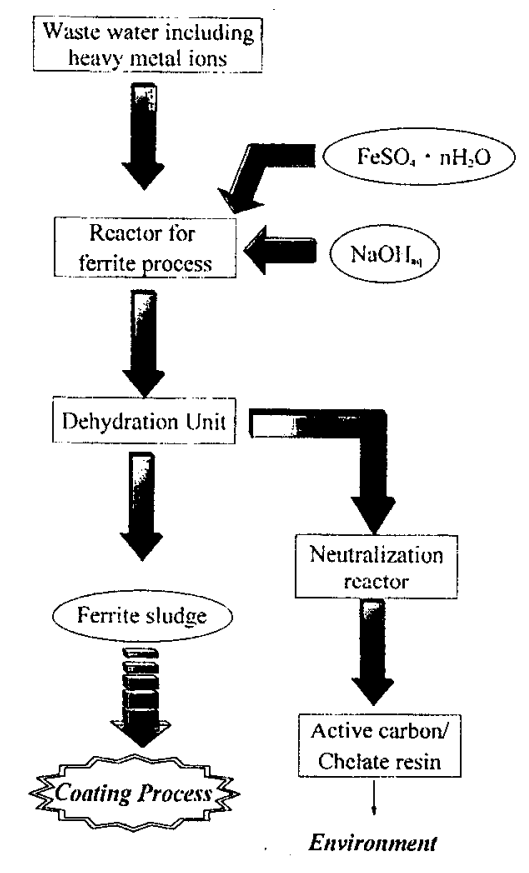

Fig. 1 Flow chart of Ferrite Process for treatment of heavy metal waste water. 
By the Ferrite Process, heavy metal ions in the waste water are incorporated into the lattice points of the spinel structure; spinel type ferrites are formed by air oxidation of hydroxide suspended solution of the waste water[1-3]. In this process, the heavy metal ions can be removed completely into the ferrite sludge whose soluble is practically zero. Ferrite Process has been practically applied for the laboratory waste water containing heavy metal ions in Japan and Korea. The ferrite sludge can be further stabilized by $\mathrm{Fe}_{3} \mathrm{O}_{4}$-coating method[4]. In this coating method, two steps of 1) addition of the $\mathrm{Fe}$ (II) aqueous solution and 2) the oxidation by passing air through the reaction suspension of the ferrite sludge, are repeated. Since the $\mathrm{Fe}_{3} \mathrm{O}_{4}$-coated ferrite sludge are very stable and no heavy metal ions are leached in the normal environmental conditions (Fig. 1).

The combined process of the Ferrite Process and the $\mathrm{Fe}_{3} \mathrm{O}_{4}$-coating method would be a technology that can solve the problem of heavy metal contamination by leaching from the sludge.

\section{III. $\mathrm{CO}_{2}$ DECOMPOSITION WITH CATION EXCESS FERRITES} FOR UTILIZATION OF CARBON AS SOLAR $\mathrm{H}_{2}$ ENERGY CARRIER

During transient from fossil energy era to solar energy era, a technology which enable us to use both fossil and solar energy will take an important role. This technology will make it possible to shift smoothly from fossil energy era to solar energy era. As one of such technologies, hybridized solar thermal plant (HST-plant) has been practically and commercially operated[5]. In this system,

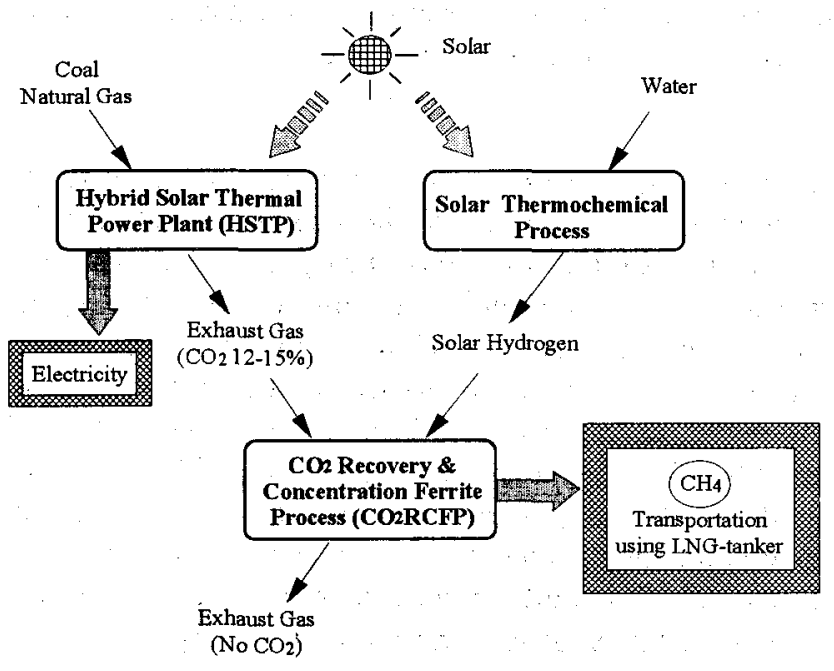

Fig 2 The combined plant of the HST and STC- $\mathrm{H}_{2}$ generates electricity (solar + fossil) and $\mathrm{H}_{2}$ (solar), and emits $\mathrm{CO}_{2}$ from the HST. solar thermal energy collected by parabolic trough is converted into electricity with fossil fuel backup, which offers prospects for economical power production (SEGS, ISCCS). This plant could be combined with the solar thermochemical plant where the concentrated solar energy is converted into solar $\mathrm{H}_{2}$ by a solar thermochemical process (STC- $\mathrm{H}_{2}$-plant). The combined plant of the HST and STC- $\mathrm{H}_{2}$ generates electricity (solar + fossil) and $\mathrm{H}_{2}$ (solar), and emits $\mathrm{CO}_{2}$ from the HST (Fig.2). The solar $\mathrm{H}_{2}$ can be made more economical in transportation by being transformed to $\mathrm{CH}_{4}$ using $\mathrm{CO}_{2}$, and can be technologically feasible; carbon takes a role of the energy carrier for the solar $\mathrm{H}_{2}[6]$. However, a technology which can recover and concentrate the $\mathrm{CO}_{2}(12-15 \%)$ in the exhaust gas from the HST should be developed.

Cation excess ferrites of $\mathrm{Fe}_{3} \mathrm{O}_{4--\delta}$ and $\mathrm{NiFe}_{2} \mathrm{O}_{4--\delta}$ decompose $\mathrm{CO}_{2}$ into carbon at $\mathrm{T}=300^{\circ} \mathrm{C}$, and the deposited carbon can be converted into $\mathrm{CH}_{4}$ by the reaction with $\mathrm{H}_{2}$ at $\mathrm{T}=300^{\circ} \mathrm{C}$. These reactions can be used for recovery and concentration of the $\mathrm{CO}_{2}$ in the exhaust gas, and can be used for conversion into $\mathrm{CH}_{4}$ at $\mathrm{T}=300^{\circ} \mathrm{C}$ (Fig.3)[7]. The conventional methanation process using catalyst can not be directly applied to the $\mathrm{CO}_{2}(15 \%)$ of the exhaust gas, since it requires a high concentration of $\mathrm{CO}_{2}$.

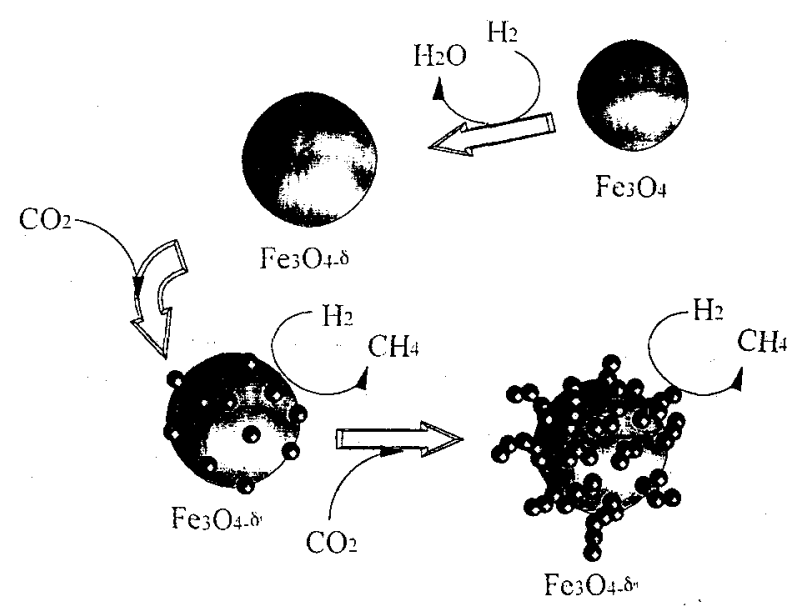

Fig. $3 \mathrm{CO}_{2}$ decomposition with an excess ferrite for utilization of carbon as solar $\mathrm{H}_{2}$ carrier.

\section{SOLAR ENERGY CONVERSION INTO $\mathrm{H}_{2}$ ENERGY}

We can reduce the metal oxides by the thermochemical decomposition into reduced forms of the metal oxides and oxygen at a higher temperature, where the Gibss free energy is negative[8]. With this reaction, the solar energy can be converted to the chemical energy of the reduced form of metal oxides, which can be successively used for water splitting into hydrogen. 


$$
\begin{aligned}
\mathrm{MO}_{\mathrm{x}} & =\mathrm{M}+1 / 2 \mathrm{xO}_{2} \\
\mathrm{M}+\mathrm{xH}_{2} \mathrm{O} & =\mathrm{MO}_{\mathrm{x}}+1 / 2 \mathrm{xH}_{2}
\end{aligned}
$$

Since those temperatures for $\mathrm{O}_{2}$ releasing step are too high to practically apply for the solar thermochemical process, the ferrite system which works at around $1200 \mathrm{~K}$ for $(\mathrm{Ni}, \mathrm{Mn})$ ferrite has been studied. The two-step watersplitting has been achieved on ( $\mathrm{Ni}, \mathrm{Mn})$ ferrite using solar furnace experimentally[9-10]. The chemical process consists of a thermochemical formation of a cation-excess (Ni,Mn) ferrite at $>1173 \mathrm{~K}$ and water splitting by the cation-excess ferrite at $<1073 \mathrm{~K}$ (Fig.4).

$(\mathrm{Ni}, \mathrm{Mn})$ ferrite $=$ cation-excess $(\mathrm{Ni}, \mathrm{Mn})$ ferrite $+1 / 2 \mathrm{\delta O}_{2}$

cation-excess (Ni,Mn) ferrite $+\delta \mathrm{H}_{2} \mathrm{O}=$ $(\mathrm{Ni}, \mathrm{Mn})$ ferrite $+\delta \mathrm{H}_{2}$

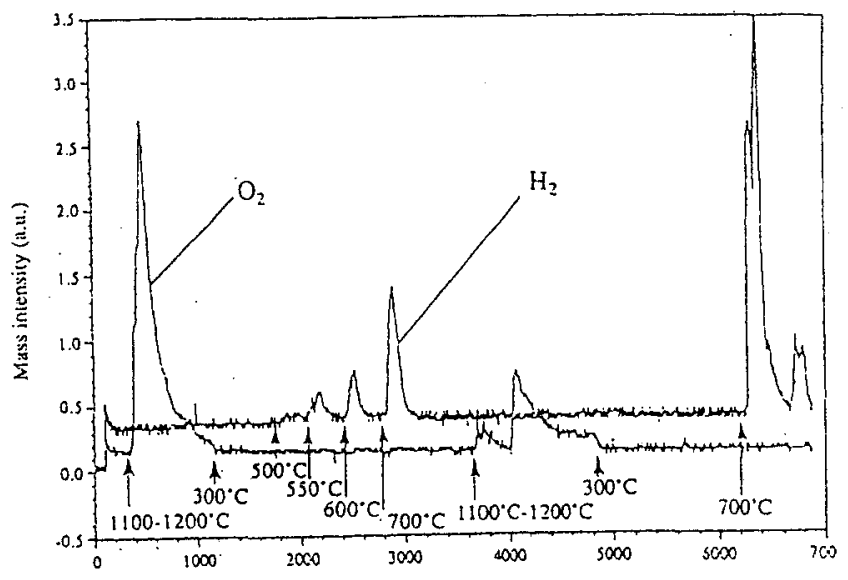

Fig. 4 The two-step water-splitting achieved on (Ni,Mn) ferrite using solar furnace.

However, the amount of hydrogen evolved in this system is small, since the water splitting is caused by the small magnitude of nonstoichiometry in the ferrite. Furthermore, the solar furnace reactions concerning $\mathrm{H}_{2}$ production studied so far are only limited to those of the $\mathrm{O}_{2}$ releasing from solid materials in two-step water splitting; there have been no reports on the $\mathrm{H}_{2}$ production from $\mathrm{H}_{2} \mathrm{O}$ to be used as solar furnace reaction. Very recently, we have found out a thermochemical process for $\mathrm{H}_{2}$ production reaction using a solid material mixture of $\mathrm{MnFe}_{2} \mathrm{O}_{4}$ and
$\mathrm{CaO}$ (or $\mathrm{Na}_{2} \mathrm{CO}_{3}$ ) at $873 \mathrm{~K}$, which can be used as the solar furnace reaction for direct solar energy absorption/conversion into $\mathrm{H}_{2}$ energy (Fig. 5).

$$
\begin{aligned}
& \mathrm{MnFe} \mathrm{O}_{4}+\mathrm{CaO}+l \mathrm{H}_{2} \mathrm{O} \rightarrow m \mathrm{Ca}_{\mathrm{x}} \mathrm{Mn}_{1-\mathrm{x}} \mathrm{Fe}_{2} \mathrm{O}_{4}+ \\
& n \mathrm{Ca}_{3}(\mathrm{Fe}, \mathrm{Mn})_{3} \mathrm{O}_{8}+l \mathrm{H}_{2} \\
& 2 \mathrm{MnFe}_{2} \mathrm{O}_{4}+3 \mathrm{Na}_{2} \mathrm{CO}_{3}+\mathrm{H}_{2} \mathrm{O}=6 \mathrm{Na}\left(\mathrm{Mn}_{1 / 3}, \mathrm{Fe}_{2 / 3}\right) \mathrm{O}_{2}+ \\
& 3 \mathrm{CO}_{2}+\mathrm{H}_{2} \\
& 6 \mathrm{Na}\left(\mathrm{Mn}_{1 / 3}, \mathrm{Fe}_{2 / 3}\right) \mathrm{O}_{2}+3 \mathrm{CO}_{2}=2 \mathrm{MnFe}_{2} \mathrm{O}_{4}+ \\
& 3 \mathrm{Na}_{2} \mathrm{CO}_{3}+1 / 2 \mathrm{O}_{2}
\end{aligned}
$$

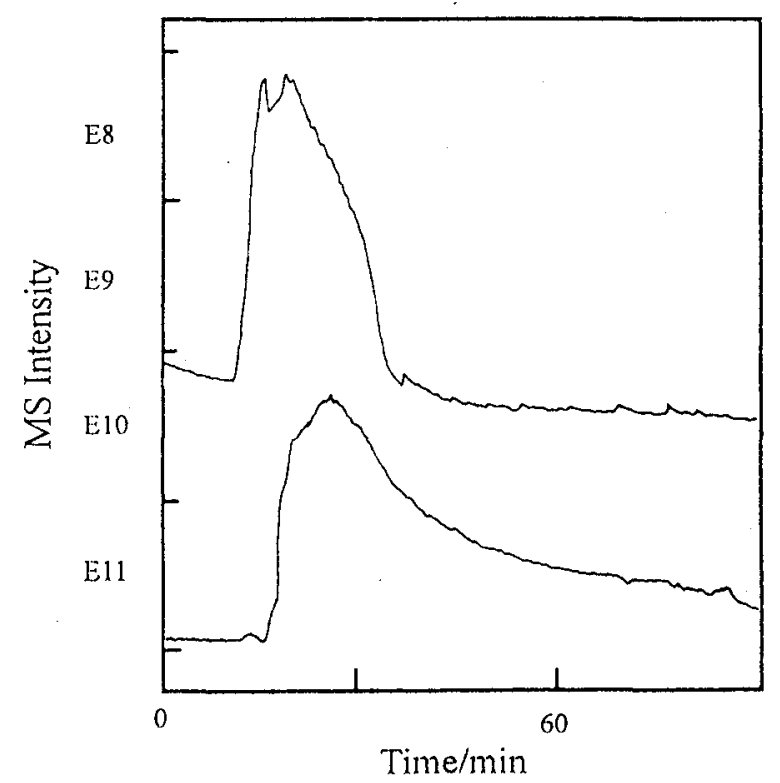

Fig. $5 \mathrm{H}_{2}$ production reaction using a solid material mixture of $\mathrm{MnFe}_{2} \mathrm{O}_{4}$ and $\mathrm{CaO}$ (or $\mathrm{Na}_{2} \mathrm{CO}_{3}$ ) at $873 \mathrm{~K}$

The $\mathrm{MnFe}_{2} \mathrm{O}_{4}-\mathrm{Na}_{2} \mathrm{CO}_{3}$ system can be cycled with a combination of the $\mathrm{O}_{2}$ releasing step, where $\mathrm{O}_{2}$ gas is released by passing $\mathrm{CO}_{2}$ gas through; $\mathrm{H}_{2}$ gas can be produced by the repetition of the two-step water splitting at $873 \mathrm{~K}$. The temperature of $873 \mathrm{~K}$ is quite lower than those studied so far on the solar furnace reaction $\left(\mathrm{O}_{2}\right.$ releasing step) in the two-step water splitting $(1500-2300 \mathrm{~K})[8]$. The elements of manganese and sodium and $\mathrm{CO}_{2}$ gas are abundant and economically available. This lower temperature and economical availability of required elements would permit further progress in the direct solar energy absorption/conversion into solar fuel $\mathrm{H}_{2}$.

\section{HYBRIDIZATION PROCESS FOR MIXING SOLAR AND FOSSIL ENERGIES}

The transition from today's fossil-fuel-based energy society to tomorrow's solar energy society can occur 
smoothly with the technology that produces mixed fuels of solar and fossil energies[11].

Coal gasification with $\mathrm{Fe}_{3} \mathrm{O}_{4}$ using solar furnace was performed to mix the solar energy with fossil energy. With this reaction, it was demonstrated that the solar energy is highly efficiently converted into chemical energy $(47 \%)$ at $1200^{\circ} \mathrm{C}$ (Fig. 6) [11-12]. This reaction will be
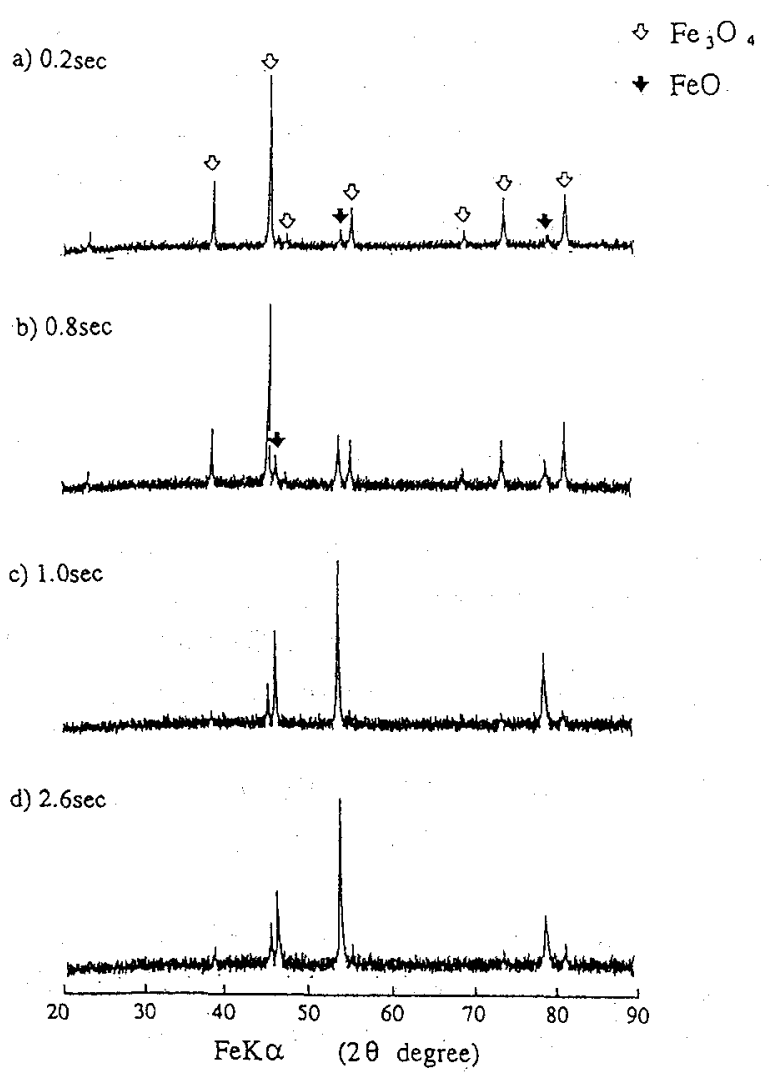

Fig. 6 Coal gasification with $\mathrm{Fe}_{3} \mathrm{O}_{4}$ using solar furnace

applicable for the new solar energy utilization process. The solar-driven endothermic reaction of coal and magnetite was studied for mixing solar and fossil energies. The overall reaction can be represented by $\mathrm{CH}_{\mathrm{x}}+\mathrm{Fe}_{3} \mathrm{O}_{4}=\mathrm{CO}+$ $3 \mathrm{FeO}+1 / 2 \mathrm{xH}_{2}$, where $\mathrm{x}$ depends on the stoichiometry of the coal utilized $(x=0.2$ in our study). Laboratory experimental studies with an equimolar mixture of anthracite coal and $\mathrm{Fe}_{3} \mathrm{O}_{4}$ powder using an infrared furnace showed rapid gas evolution above about $1473 \mathrm{~K}$ and $1 \mathrm{bar}$, producing $\mathrm{FeO}(\mathrm{s})$ and a gas mixture containing a $\mathrm{CO} / \mathrm{CO}_{2}$ molar ratio at 4.5. Solar-driven experiments were conducted using a high-flux solar furnace. Pelleted samples were directly exposed for short time intervals to a solar flux irradiation of $300 \mathrm{~W} / \mathrm{cm}^{2}$. The carbon content decreased rapidly after only 1 second exposure, suggesting efficient heat transfer and chemical conversion by direct absorption of concentrated solar energy at the reaction site. The proposed solar thermochemical process offers the possibility of performing simultaneously gasification of coal and reduction of iron oxide and also producing a fuel with an upgraded calorific value.

\section{REFERENCES}

[1] T.Katsura, Y.Tamaura and H. Terada, Industrial Water (Jpn), 233(4), 16, 1977.

[2] Y.Tamaur, M.Kitamura and H.Takatsuki, Industrial Water (Jpn), 367(4), 29, 1989.

[3] T.Yoshida and Y. Tamaura, Proc. of 16th Int. conf. on Ferrites (ICF 6), pp. 256-261, Tokyo \& Kyoto, 1992.

[4] M.Abe, Proc. of 16th Int. conf. on Ferrites (ICF 6), "Ferrite Plating: A Versatile Preparation Technique of Ferrite Films in Aqueous Solution at Low Temperature (<100C)", pp.472-477, Tokyo \& Kyoto, 1992.

[5] W.Grasse, M.Becker, P.Kuhn, C.Tyner,

IEA SolarPACES Annual Report, 62-63 (Deutshce Forschungsanstalt fur Luft- und Raumfahrt e.V., Koln, 1995.

[6] Y.Tamaura and M.Tsuji, Proc. of IEA/JSER Int. Conf. on Energy and Environment, Osaka, pp.59-63, 1996.

[7] Y. Tamaura, Proc. of 16th Int. conf. on Ferrites (ICF 6), pp.195-198, Tokyo \& Kyoto, 1992.

[8] A. Steinfeld, P.Kuhn, A. Reller, R.Palumbo, J.Murray, Y.Tamaura, Hydrogen Eenrgy Progess XI, 601-609, 1996. [9] Y.Tamaura, A.Steinfeld, P.Kuhn, K.Ehrensberger, Energy-The International Journal, 20, 325-330, 1995.

[10] M.Kojima, T.Sano, Y.Wada, T.Yamamoto, M.Tsuji, Y.Tamaura, J. Phys. Chem. Solids, 57, 1757-1763, 1996.

[11] Y.Tamaura, "Solar Chemical Technolgoy for Hybridization with Coal gasification/Liquefaction", Proc. of the 13th Conference on Energy System Economics, pp.401-403 (in Japanese), Tokyo, Jan. 1998.

[12] Y.Tamaura, Y.Wada, M.Tsuji, K.Ehrensberger, A.Steifeld, Energy ,22, 337, 1997. 